\title{
Alpha-1 antitrypsin as a risk marker in SARS-CoV-2 infection
}

José María Hernández Pérez ${ }^{1}$, Juan Marco Figueira Gonçálves ${ }^{1}$, Yolanda Ramallo Fariña ${ }^{2}$

${ }^{1}$ University Hospital Nuestra Señora de Candelaria, Spain

${ }^{2}$ Foundation of the Canary Islands Health Research Institute (FIISC), Spain

Submitted: 26 January 2021, Accepted: 11 May 2021

Online publication: 22 May 2021

Arch Med Sci 2021; 17 (4): 1134-1136

DOI: https://doi.org/10.5114/aoms/136562

Copyright $\odot 2021$ Termedia \& Banach

The SARS-CoV-2 virus has infected millions of people worldwide. Given its unpredictability, much research is being focused on potential indicators of a poor course of the resulting disease, COVID-19. Various serum biomarkers, e.g., total leukocyte and lymphocyte counts, lactate dehydrogenase (LDH), D-dimer, procalcitonin, troponin I and ferritin levels, seem to provide support for decision making on process severity and the need of intensive care unit (ICU) transfer, and even predict mortality [1, 2].

Alpha- 1 antitrypsin (AAT) is a water-soluble glycoprotein, mainly synthesised by hepatocytes, and provides the largest part of anti-protease activity to the human body. Being an acute phase reactant, its plasma levels increase in response to inflammatory or infectious stimuli and persist for 7 to 15 days [3]. In addition to its anti-inflammatory activity, AAT has anti-microbial properties, as its carboxy-terminal 20 amino-acid residues can interfere with virus replication and infectivity, e.g., of the human immunodeficiency virus [4]. A similar response could be expected in SARS-CoV2-infected patients, although only a few studies have focused on this aspect so far.

Accordingly, we wanted to explore AAT levels as a potential risk marker for severe SARS-CoV-2 infections with a poor course. To this end, a prospective, observational, descriptive study was performed on patients admitted consecutively to our hospital with SARS-CoV-2 pneumonia. The study was conducted in accordance with the Declaration of Helsinki and approved by the hospital's ethics committee. Diagnosis was established through real-time, reverse polymerase chain reaction (RT-PCR) for SARSCoV-2 in samples from nasopharyngeal smears, paralleled by lung consolidation on current chest radiography. The criteria inclusion comprised AAT, LDH, ferritin, D-dimer, total lymphocyte count, C-reactive protein and interleukin 6 (IL-6) determination in all patients within $48 \mathrm{~h}$ after admission, an RT-PCR confirmed diagnosis and radiological diagnoses pneumonia. Patients in whom some of the established measurement parameters were missing, or performed later than $48 \mathrm{~h}$ after admission, as well as patients who did not present radiological infiltrates on admission were discarded. Emerging adult respiratory distress syndrome (ARDS), determined by pulse oximetric saturation/fraction of inspired oxygen ratio $\left(\mathrm{SpO}_{2} / \mathrm{FiO}_{2}\right)<300$ [5], was considered the reference parameter for a poor disease course.

The study sample consisted of 45 patients; $37.8 \%$ were women and $62.2 \%$ men. Their median age was $59 \pm 11.49$ years. The mean time from onset of symptom to hospital admission was $5.12 \pm 3.48$ days; $37.8 \%$ of

\author{
Corresponding author: \\ José María Hernández \\ Pérez MD, PhD \\ University Hospital \\ Nuestra Señora \\ de Candelaria \\ Spain \\ E-mail: jmherper@hotmail. \\ com
}




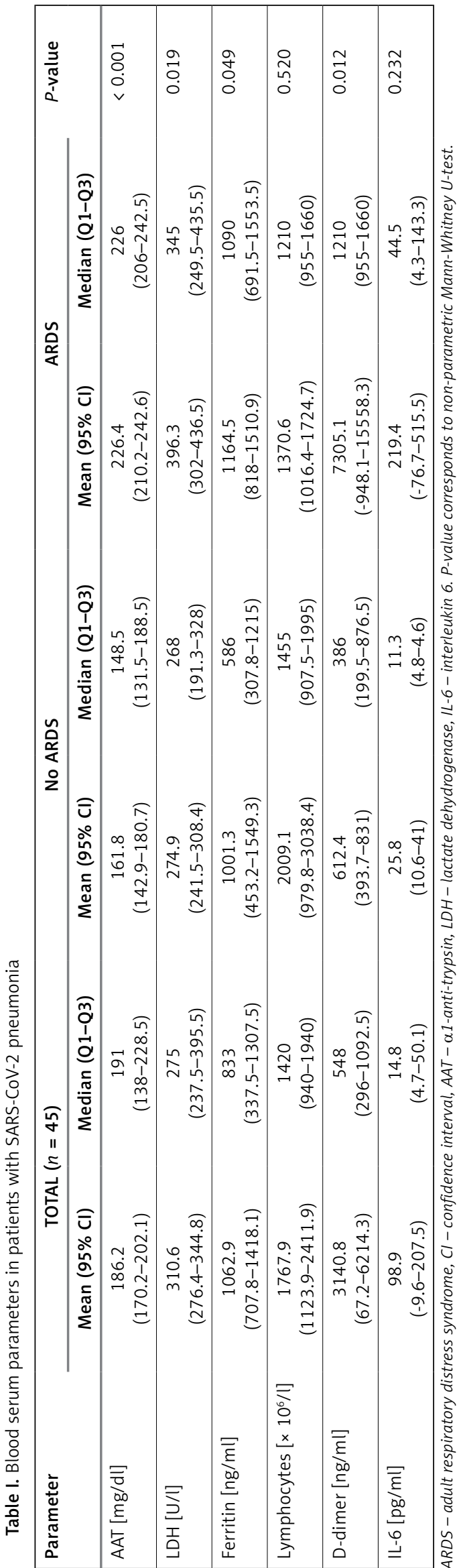

the patients developed ARDS, $11.11 \%$ eventually needed transfer to the ICU. The overall mortality was $2.22 \%$. Patients who developed ARDS had significantly higher levels of AAT, LDH, ferritin and D-dimer than the rest (Table I). AAT levels $>200$ $\mathrm{mg} / \mathrm{dl}$, i.e. above the upper reference level, correlated with emerging ARDS with an odds ratio (OR) of 30.9 (95\% confidence interval $(95 \% \mathrm{Cl}$ ): 3.17-301.55). Applying multivariate analysis, only AAT correlated significantly (in $82.2 \%$ of the cases) with ARDS (OR = 1.026, 95\% Cl: 1.004-1.047).

Only a few studies have assessed AAT in SARSCoV-2 infection so far. McElvaney et al. [6] reported a higher IL-6/AAT ratio in patients who needed ICU transfer than in subjects with a more favourable disease course.

Other authors, such as Wettstein et al. [7], have demonstrated in vitro that AAT is capable of inhibiting SARS-CoV-2 replication in infected cells. These cells increase serine transmembrane protease 2 (STP2) expression, which in turn has an anti-inflammatory effect that facilitates virus entry into the cells. AAT appears to act by inhibiting STP2, thus hampering viral uptake. Our study indicated that AAT levels > $200 \mathrm{mg} / \mathrm{dl}$ constitute an important predictor of ARDS and thus a potential means for patient monitoring.

To date, only a few studies have evaluated AAT as a prognostic marker. Age, comorbidities, lymphopenia, increased inflammatory biomarkers (e.g., C-reactive protein, serum ferritin and erythrocyte sedimentation rate) and elevated aspartate aminotransferase, creatinine and LDH levels have been correlated with ARDS in patients with COVID-19 [8].

In conclusion, the results of our study indicate that AAT may be a reliable marker in predicting the occurrence of ARDS and therefore the disease course in patients affected by SARS-CoV-2, although further studies with a larger sample size are needed to confirm these findings.

\section{Conflict of interest}

The authors declare no conflict of interest.

\section{References}

1. Wang D, Hu B, Hu C, et al. Clinical characteristics of 138 hospitalized patients with 2019 novel coronavirus-infected pneumonia in Wuhan, China. JAMA 2020; 323: 1061-9.

2. Figueira Gonçalves JM, Hernández Pérez JM, Acosta Sorensen $\mathrm{M}$, et al. Biomarkers of acute respiratory distress syndrome in adults hospitalised for severe SARS-CoV-2 infection in Tenerife Island, Spain. BMC Res Notes 2020; 13: 555.

3. Blanco I, Lara B. Déficit de alfa-1 antitripsina: fisiopatología, enfermedades relacionadas y tratamiento. RESPIRA. Barcelona 2016; 327. 
4. Congote LF. The C-terminal 26-residue peptide of serpin A1 is an inhibitor of HIV-1.Biochem Biophys Res Commun 2006; 343: 617-22.

5. Schmidt MF, Gernand J, Kakarala R. The use of the pulse oximetric saturation to fraction of inspired oxygen ratio in an automated acute respiratory distress syndrome screening tool. J Crit Care 2015; 30: 486-90.

6. McElvaney OJ, McEvoy NL, McElvaney OF, et al. Characterization of the inflammatory response to severe COVID-19 illness. Am J Respir Crit Care Med 2020; 202: 812-21.

7. Wettstein L, Conzelmann C, Müller JA, et al. Alpha-1 antitrypsin inhibits SARS-CoV-2 infection. bioRxiv preprint doi: https://doi.org/10.1101/2020.07.02.183764.

8. Poggiali E, Zaino D, Immovilli P, et al. Lactate dehydrogenase and $\mathrm{C}$-reactive protein as predictors of respiratory failure in COVID-19 patients. Clin Chim Acta 2020; 509: $135-8$ 